\title{
Ciencia e ideología. Entrecruzamientos críticos en la obra de Herbert Marcuse
}

\author{
Science and ideology. \\ Critical crisscrossing in Herbert Marcuse's work \\ NATALIA FISCHETTI \\ CONICET (Argentina)
}

Recibido: 15/11/12 Aprobado: 06/06/13

\section{RESUMEN}

La ideología producida por la ciencia y la tecnología, por la racionalidad tecnológica, es el concepto que estructura gran parte del pensamiento de Herbert Marcuse. La noción de ideología vinculada a la ciencia y la tecnología interviene en el debate contemporáneo recuperando una lectura de los Grundrisse de 1857-1858 de Marx que coloca la noción de automatización como elemento clave para comprender dialécticamente el vínculo entre la ciencia, la tecnología y la ideología, actualizando la función crítica de ésta última. Proponemos entonces que este cruce entre ideología y ciencia desde una asimilación de la crítica de las ideologías con la dialéctica y la teoría crítica en Marcuse permite pensar conjuntamente la epistemología y la política.

\section{PALABRAS CLAVE}

CIENCIA, IDEOLOGÍA, DIALÉCTICA, AUTOMATIZACIÓN

\footnotetext{
ABSTRACT

The ideology produced by science and technology, due to technological rationality, is the concept that structures great part of the thinking of Herbert Marcuse. The concept of ideology related to science and technology takes part in the contemporary debate retaking a reading of the Grundrisse of 1857-1858 by Marx that develops the concept of automation as a key element to understand the link between science, technology and ideology in a dialectical way, updating the

(C) Contrastes. Revista Internacional de Filosofia, vol. XIX-Nº1 (2014), pp. 123-138. ISSN: 1136-4076 Departamento de Filosofía, Universidad de Málaga, Facultad de Filosofía y Letras

Campus de Teatinos, E-29071 Málaga (España)
} 
critical function of the latter. We suggest that this crisscrossing between ideology and science, from an assimilation of the criticism of ideologies and the dialectics and the critical theory in Marcuse, allows a joint thinking of epistemology and politics.

KEY WORDS

SCIENCE, IDEOLOGY, DIALECTICS, AUTOMATION

\section{DialÉCtiCA DE LA RACIONALIDAD TECNOLÓGICA Y LA IDEOLOGÍA}

EN ESTE TEXTO QUEREMOS mostrar una lectura dialéctica de la noción de ideología en la obra de Herbert Marcuse, en función de sus propias lecturas de la obra de Karl Marx. La crítica de las ideologías se entrecruza para el frankfurteano con la problemática epistemológico-política de la ciencia y la tecnología en las sociedades contemporáneas. Para ello revisaremos algunos textos clave de la obra marxiana y de la marcuseana para finalmente plantear algunas repercusiones de esta lectura del concepto de ideología en el debate filosófico político.

En el célebre apartado del tomo I de El Capital (1867) denominado «El carácter fetichista de la mercancía y su secreto», Marx expone lo que importantes intérpretes de la noción de ideología, como Jorge Larraín (1979) y Terry Eagleton (1997), consideran constituye una tercera etapa del desarrollo del concepto en su obra.

Para Marx, la mercancía reviste un carácter místico que la torna en fetiche.

Lo misterioso de la forma mercantil consiste sencillamente, pues, en que la misma refleja ante los hombres el carácter social de su propio trabajo como caracteres objetivos inherentes a los productos del trabajo, como propiedades sociales naturales de dichas cosas, y, por ende, en que también refleja la relación social que media entre los productores y el trabajo global, como una relación social entre los objetos, existente al margen de los productores. Es por medio de este quid pro quo (tomar una cosa por otra) como los productos del trabajo se convierten en mercancías, en cosas sensorialmente suprasensibles o sociales. ${ }^{1}$

De este modo, la mercancía antepone su valor de cambio al valor de uso y los hombres se someten a ella en lugar de controlarla en tanto cosa. Afirma Marx que el dinero, como la forma más acabada de la mercancía, vela, oculta el carácter social de los trabajos privados, abstrayendo las desigualdades reales bajo la forma de la igualdad del trabajo abstracto.

Para Larraín en esta etapa de la obra de Marx se explica la ideología en tanto inversión real, y no sólo mental, porque la explotación que ocurre al nivel

1 MARX, Karl. [1867] El Capital. Tomo I/Vol. 1. Madrid, Siglo XXI, 2010, p. 88. 
de la producción es negada en el mercado libre, a nivel de la circulación de las mercancías. Es decir que lo que se oculta son las relaciones reales invertidas: la contradicción presentada entre el carácter social de la producción (trabajo) y el carácter privado de la apropiación (capital) constituye la contradicción principal del capitalismo. La superación del capitalismo sólo puede ocurrir con la modificación práctica de las contradicciones materiales, como el único modo de hacer estallar su ideología política.

Eagleton en su Ideología, explicita que «en la sociedad capitalista las relaciones sociales reales entre los seres humanos están regidas por las interacciones aparentemente autónomas de las mercancías que producen». ${ }^{2}$ Señala que las consecuencias del fetichismo de la mercancía son, como ya se dijo, el ocultamiento del carácter social del trabajo, pero también la fragmentación de la sociedad en tanto totalidad. Además, si la sociedad se encuentra dominada por cosas, se naturaliza y se percibe como inmodificable y no como lo que es, una construcción humana histórica. En el fetichismo la mente refleja una inversión en la propia realidad en la cual el capital muerto controla el trabajo vivo.

Para Marcuse, en El hombre unidimensional, en relación con las posibilidades de pacificación propias de lo que llama «la verdadera finalidad de la tecnología», advierte en contra del «fetichismo tecnológico». Es decir que la ideología se ha desplazado, en la sociedad industrial altamente desarrollada, de la mercancía a la tecnología.

Tal fetichismo ha sido exhibido recientemente sobre todo entre los críticos marxistas de la sociedad industrial contemporánea y se expresa a través de ideas sobre la futura omnipotencia del hombre tecnológico, de un «Eros tecnológico», etc. Lo medularmente cierto en estas ideas exige una resuelta denuncia de la mistificación que expresan. La técnica, como universo de instrumentos, puede aumentar tanto la debilidad como el poder del hombre. ${ }^{3}$

En relación con esta tesis de Marcuse es que queremos presentar como clave para la interpretación del concepto de ideología en su obra, vinculada con la racionalidad tecnológica, otro importante texto de Marx. En el capítulo denominado «El Capital» en Elementos fundamentales para la crítica de la economía política (Grundrisse) de 1857-1858, Marx interpreta dialécticamente la maquinaria, la ciencia y la técnica en el sistema productivo. Queremos mostrar que estos textos funcionan como mediadores de la ideología en Marcuse y

2 Eagleton, Terry. [1997] Ideología. Una introducción. Barcelona, Paidós, 2005, p. 118.

3 Marcuse, Herbert. El hombre unidimensional. Ensayo sobre la Ideología de la Sociedad Industrial Avanzada. México, Joaquín Mortiz, 1969. Edición original: (1964) One-Dimensional Man (Boston: Beacon Press). p. 250 
permiten poner en entredicho ciertas interpretaciones extremas de la ideología en su obra, tal como señalaremos más adelante.

Marcuse trabaja su discurso de la ideología según una metodología dialéctica, entre lo real y lo posible. Esta dialéctica se encuentra ya en el propio Marx, lo que permitiría afirmar que la «dialéctica», la «teoría crítica» y la «crítica de las ideologías», pueden ser tomadas aquí como sinónimos en tanto teórica y metodológicamente centrales a la obra de Marcuse. La ideología propia de la racionalidad tecnológica es tanto el final de la dialéctica en el sentido de la definitiva afirmación de lo dado y ocultamiento de las contradicciones, como la superación de lo real en la vislumbre de lo posible. Intentamos mostrar que en relación al concepto de ideología, Marcuse no abandona tampoco su fidelidad a un método que le permite fluir rigurosamente por la teoría crítica marxista. Queremos enfatizar nuestra idea de que toma elementos de la obra de Marx y los jerarquiza en función de sus preocupaciones acerca de los cambios producidos en las sociedades industriales de un siglo, el de Marx, al otro, el suyo.

\section{ANTECEDENTES: MarX, LA IDEOLOGÍA Y LA CIENCIA}

En los Grundrisse, Marx analiza la ciencia y la técnica como parte fundamental del sistema de producción del capital. Con relación al capital fijo (capital fixe), su culminación es la maquinaria, que alcanza su plenitud en la automatización. La máquina se distingue del instrumento, que requiere de la habilidad del obrero, porque opera automáticamente en función de la ciencia que le da origen y finalidad, ciencia que el obrero desconoce. «La ciencia, que obliga a los miembros inanimados de la máquina - merced a su construcción-a operar como un autómata, conforme a un fin, no existe en la conciencia del obrero, sino que opera a través de la máquina, como poder ajeno, como poder de la máquina misma, sobre aquél» ${ }^{4}$. El trabajo, con la culminación de la tendencia necesaria del capital en la automatización, deja de ser el elemento central del proceso de producción. Así, la ciencia y la técnica producen un crecimiento del sistema de producción con la maquinaria que termina negando al trabajo como medio del capital. La maquinaria se constituye en la fuerza productiva misma. Para Marx, «el proceso entero de producción, empero, no aparece como subsumido bajo la habilidad directa del obrero, sino como aplicación tecnológica de la ciencia. Darle a la producción un carácter científico es, por ende, la tendencia del capital, y se reduce el trabajo a mero momento de ese proceso». ${ }^{5}$ La ciencia y la técnica como centrales al sistema productivo son la tendencia

4 Marx, Karl. [1931-1941] Elementos fundamentales para la crítica de la economía política (Borrador), 1857-1858. Volumen 2. (Grundrisse). Madrid, Siglo XXI, 1972, p. 219.

5 Ibid.p. 221 
del capital, lo que no significa que el capital sea la mejor forma en que puede desarrollarse la maquinaria en tanto sistema de producción.

Hemos recalcado ya que el trabajo inmediato del obrero, medido cuantitativamente, se ve subsumido frente a la tendencia del capital de determinarse por el capital fijo, es decir la maquinaria. En este sentido lo que queremos decir es que

El trabajo inmediato se ve reducido cuantitativamente a una proporción más exigua, y cualitativamente a un momento sin duda imprescindible, pero subalterno frente al trabajo científico general, a la aplicación tecnológica de las ciencias naturales por un lado, y por otro frente a la fuerza productiva general resultante de la estructuración social de la producción global, fuerza productiva que aparece como don natural del trabajo social (aunque [sea, en realidad, un] producto histórico). El capital trabaja, así, en favor de su propia disolución como forma dominante de la producción. ${ }^{6}$

Al producirse históricamente una transformación del proceso de producción en un proceso científico-técnico, se reduce la necesidad del trabajo individual en beneficio del trabajo social. Lo interesante para Marx, y para Marcuse, es que el capital genera su propia contradicción al requerir, con el aumento de la automatización de las fuerzas productivas, cada vez menos fuerza viva de trabajo, menos energía humana. Afirma que «Esto redundará en beneficio del trabajo emancipado y es la condición de su emancipación» ${ }^{7}$. Pero aunque la maquinaria como medio del trabajo puede volver autónomo al obrero si es su propietario, la contradicción actual radica en que

El medio de trabajo vuelve autónomo al trabajador, lo pone como propietario. La maquinaria - en cuanto capital fixe- lo pone como no autónomo, como objeto de la apropiación. Este efecto de la maquinaria sólo se produce en la medida en que está determinada como capital fixe, y está determinada en cuanto tal sólo porque el obrero se relaciona con ella como asalariado, y el individuo activo en general como mero obrero. ${ }^{8}$

Si la riqueza, el capital, se funda, en tiempos de Marx, en el robo del trabajo ajeno, en la alienación del obrero, entonces esta riqueza es pobreza en relación con las posibilidades que vislumbra para el sistema de producción en función de los avances de la ciencia y la tecnología, y su progreso en el dominio de la naturaleza. La producción fundada en el tiempo de trabajo inmediato y en 
el valor de cambio caería en favor de un sistema de producción automatizado gracias a los desarrollos científico-técnicos.

Desarrollo libre de las individualidades, y por ende no reducción del tiempo de trabajo necesario con miras a poner plustrabajo, sino en general reducción del trabajo necesario de la sociedad a un mínimo, al cual corresponde entonces la formación artística, científica, etc., de los individuos gracias al tiempo que se ha vuelto libre y a los medios creados para todos. ${ }^{9}$

Sin embargo, por ahora, afirma Marx, se mantiene la contradicción intrínseca del capital acerca del tiempo de trabajo como la única fuente de la riqueza, aun frente a la tendencia de su obsolescencia. Esto es así porque tanto los individuos como la ciencia se le aparecen como medios y, aunque sea capaz de crear tiempo libre, se las ingenia para convertirlo en trabajo extra para la mayoría. En un sistema de producción propiedad de los obreros, es el tiempo libre la medida de la riqueza y no el tiempo de trabajo como para el capital.

Es aquí donde se encuentra la ideología vinculada a la tendencia del capital de convertirse en capital fijo o maquinaria, a la tendencia de que la ciencia sea el motor del sistema productivo y no el tiempo de los trabajadores. La ideología se encuentra en la inversión real, y no sólo mental, dice Marx, de esta tendencia. En lugar de producirse la objetivación del trabajo se mantiene la alienación por la apropiación del trabajo ajeno por parte del capital.

Pero evidentemente este proceso de inversión es tan sólo una necesidad histórica, una simple necesidad para el desarrollo de las fuerzas productivas desde determinada base o punto de partida histórico, pero en modo alguno una necesidad absoluta de la producción; más bien es una necesidad pasajera y el resultado y la finalidad (inmanente) de este proceso es abolir esa misma base, así como esa forma del proceso. ${ }^{10}$

En definitiva, no son las máquinas, engendradas por la ciencia, las que son demonizadas por Marx, sino el hecho de que el capital perdure en su alienación de los obreros por el robo de su tiempo de trabajo aun cuando sea posible generar tiempo libre. Incluso afirma «las máquinas no cesarán de ser agentes de la producción social cuando, por ejemplo, se conviertan en propiedad de los obreros asociados». ${ }^{11}$ La práctica revolucionaria que generara una nueva base de la producción surgida del proceso histórico, se constituiría en una concepción no ideológica. Mientras tanto la ideología política del capital consiste en 
el ocultamiento de la contradicción que hemos señalado entre el capital, como propiedad privada, y el trabajo, en su carácter social.

\section{CienCIA E IDEOLOGÍA EN LA DIALÉCTICA MARCUSEANA}

En palabras de Marcuse:

En la consumación de la automatización, se encuentra la frontera última del capitalismo. Como lo vio Marx ya antes de El Capital, la automatización completa del trabajo solamente necesario es incompatible con el mantenimiento del capitalismo. Esta tendencia, para indicar la cual la palabra «automatización» es sólo un símbolo compendioso, por la cual el trabajo físico necesario, trabajo alienado, se sustrae cada vez más del proceso material de producción, esa tendencia conduce -y aquí llego efectivamente a posibilidades «utópicas», y hemos de enfrentamos con ellas para ver qué es lo que de verdad está en juego- al experimento total en el marco histórico y a nivel histórico ${ }^{12}$.

La apuesta aquí es que este análisis de la ciencia y la técnica, vinculadas a la noción de «inversión real» tal como lo hemos recuperado de Marx, constituyen el cuerpo del análisis de la ideología por Marcuse en el sentido dialéctico de que son, al mismo tiempo, falsa conciencia y ocultamiento de las contradicciones, como posibilidad de la emancipación, considerando el hecho de que su participación en el sistema productivo ha sido, es y será históricamente determinada.

En un artículo editado póstumamente, escrito por Marcuse en colaboración con Franz Neumann entre 1941 y 1942, donde se sintetizan las teorías del cambio social, se propone una interpretación dialéctica de la ideología en Marx en el sentido señalado. Allí expresan que con relación a las fuerzas productivas, Marx quería mostrar la distancia existente entre el desarrollo real y potencial de la tecnología y la industria y la dirección en que es posible orientar este desarrollo: hacia la explotación o hacia la liberación de los individuos. Encuentran aquí la clave para la función de la ideología con relación al cambio social.

Las ideas prevalecientes en una sociedad, no sólo no son una mera 'ilusión', sino que proporcionan una norma importante para el carácter objetivo de las contradicciones sociales y para la dirección en la cual se puede buscar una solución. Marx mismo empleaba la ideología de la sociedad de clase media de esta manera. Esa ideología sostenía que ella organizaba la sociedad según principios de libertad, igualdad, intercambio justo e interés propio, y concebía así los verdaderos principios de una sociedad libre y racional. Pero a causa de las relaciones en las que la clase media había ordenado el proceso productivo, estos principios de manera

12 Marcuse, Herbert. El final de la utopía. Barcelona, Planeta Agostini, 1986. Edición original: (1967) Das Ende der Utopie (West Berlin: Maikowski). p. 13 
inexorable se convertían en su opuesto y creaban servidumbre, desigualdad, injusticia y explotación. ${ }^{13}$

Es decir que la ideología en el sistema capitalista cumple una doble función: en tanto ilusión encubridora y en tanto orientadora del proceso emancipatorio.

La crítica a la ideología de la sociedad industrial avanzada atraviesa toda la obra de Marcuse, sin embargo, en los años 60, se patentiza en dos textos clave para la comprensión de su problemática. El primero de ellos es una contribución que presentó en el Quinto Congreso Mundial de Sociología en Washington en 1962 y que Kurt Lenk ${ }^{14}$ publica en su célebre texto sobre la ideología. El segundo texto emblemático es El hombre unidimensional, cuyo subtítulo anticipa la discusión sobre la ideología. La intención es mostrar que, mediada por la racionalidad tecnológica, la ideología se convierte en la anulación de la dialéctica. Para Marcuse, la dialéctica entre lo real y lo posible ha sido eliminada de la sociedad industrial contemporánea porque el protagonismo de una racionalidad científico-tecnológica permite producir la ideología de creer que los hechos y sus conceptos no tienen historia, en el sentido de que su devenir histórico no tiene interés porque se han desarrollado del único y mejor modo posible, según la idea de progreso vigente, y son objetivamente reales y por tanto verdaderos. Pero, al mismo tiempo, la ciencia y la técnica constituyen la utopía (como lugar de la posibilidad) de la emancipación.

En la década del 60, frente a las tesis del fin de las ideologías tales como la de Daniel Bell, ${ }^{15}$ Marcuse coloca la noción de ideología como central de ese momento del desarrollo capitalista. De este modo, en el citado texto de 1962 anticipa de modo sintético el desarrollo de El hombre unidimensional. $\mathrm{Su}$ preocupación gira en torno a la pérdida de la función de la teoría crítica como oposición, como negación de la sociedad establecida por la integración, la asimilación de la clase trabajadora al sistema, ejercida por la sociedad industrial avanzada. Marcuse busca redefinir el concepto de ideología desde una perspectiva que permita «historizar», introducir la historia en el concepto, para renovar su función crítica en los años 60, en un momento en el que se busca diluir la noción misma. Retoma aquí nuevamente el concepto de Marx de ideología en el doble sentido señalado:

13 Marcuse, Herbert. Guerra, Tecnología y Fascismo. Textos inéditos. Medellín, Universidad de Antioquía, 2001. p. 168

14 Marcuse, Herbert. «Acerca del problema de la ideología en la sociedad industrial altamente desarrollada» (1962) En: LENK, Kurt. El concepto de ideología. [1971] Buenos Aires, Amorrortu, 2000.

15 Bell, Daniel. (1960) El fin de las ideologías. Madrid, Tecnos, 1964. 
Dentro de la concepción marxista, 'ideología' significa una conciencia que se adelanta a la realidad presente en cuanto proyecta ideas (p. ej., libertad, igualdad, felicidad) que fueron posibilitadas, pero al mismo tiempo estorbadas, por el desarrollo social. Incapaz de modificar por sí misma esa situación, y compelida por la realidad social, la conciencia ideológica es una 'conciencia falsa', pero como tal anticipa de manera idealista posibilidades históricas que son reprimidas por la realidad del presente. ${ }^{16}$

Pero, para Marcuse, esta definición de la ideología ha perdido vigencia en la sociedad industrial avanzada porque en ella las ideas señaladas han sido resignificadas para que formen parte de las instituciones sociales tal como se encuentran, es decir, sin necesidad de que sean transformadas. Las ideas que buscaban una realización de la humanidad fuera de la instrumentalidad y del trabajo forzoso y de la alienación, han sido modificadas hasta volverse funcionales a la sociedad. Las ideas de libertad, felicidad e igualdad se encuentran aún vinculadas al sistema de producción pero ahora asociadas al consumo y al lucro. Es decir que en la sociedad industrial avanzada se ha eliminado la tensión dialéctica entre los opuestos como la producción y la destrucción, la liberación y la esclavitud, lo cual significa que los primeros son arrastrados, son instrumentalizados en función de los segundos. El denominador común que Marcuse encuentra entre los polos de la tensión eliminada es «la industria automatizada como base material, técnica, de la sociedad», ${ }^{17}$ tal como lo hemos explicado a partir de los Grundrisse.

«Esta sociedad tecnológica es el último estadio en la realización de un proyecto histórico: la experimentación, transformación y organización de la naturaleza en cuanto vasto objeto de dominio». ${ }^{18} \mathrm{El}$ asunto es que este proyecto ha trascendido al capitalismo y abarca también a las sociedades comunistas.

La organización tecnológica del hombre y la naturaleza constituyen la racionalidad del sistema en la sociedad industrial altamente desarrollada en la que la intensidad de la ideología se revela como la incapacidad de los sujetos para rebelarse contra los abusos de la misma porque se identifican interiormente con ella. La ideología se ha vuelto un arma material en el sentido de que la forma de producción dominante produce la conciencia falsa que la sustenta y rechaza lo que se le opone. La racionalidad tecnológica en tanto racionalidad política de cohesión, control y contención sociales, domina la vida pública y la privada y favorece una comodidad racional y «democrática» que en última instancia revelan nuevos mecanismos de esclavitud. Retomando a Marx afirma que, aunque la técnica, los procesos tecnológicos, podrían liberar a la humani-

16 Marcuse, 2000, op.cit, p. 347

17 Ibid. p. 348

18 Idem 
dad del trabajo forzoso, en la sociedad industrial avanzada, cumple una función totalitaria en el sentido de que coordina y manipula las necesidades aunque de un modo no terrorista. Tal como desarrolla en El hombre unidimensional, las necesidades que superan lo biológico y que son históricas son inauténticas si se imponen a los individuos desde intereses sociales.

Las formas dominantes del control social son tecnológicas en el sentido de que se presentan como racionales porque benefician a todos y de este modo los individuos se identifican inmediatamente, de forma mecánica, mimética, producto de una manipulación científica, con su sociedad. Así, los sujetos se alienan en una única dimensión que es la que su sociedad les presenta como real y verdadera. La sociedad industrial avanzada es más ideológica porque la ideología se encuentra dentro del propio proceso productivo. El aspecto político de la racionalidad tecnológica dominante se manifiesta en que es un buen tipo de vida que combate el cambio cualitativo. Esta tendencia está relacionada con el método científico: operacionalismo y conductismo como teoría y práctica de la contención.

Nosotros queremos señalar la centralidad de la noción de ideología para la comprensión de la crítica a la racionalidad tecnológica y viceversa: el aporte a la discusión sobre el concepto de ideología en la década del 60 desde la interpretación dialéctica de la ciencia y la tecnología. Esta interpretación tiene la ventaja de no ser reduccionista. No es reduccionista porque no oculta la dialéctica.

En El hombre unidimensional, se pone de manifiesto sobre todo la visión de la ideología en el sentido de ilusión, de falsa conciencia, de ocultamiento en relación a la función que en la sociedad industrial avanzada desempeña la racionalidad tecnológica. Esto considerando el auge del positivismo en las versiones de la analítica y el operacionalismo que constituyen la unidimensionalidad de una existencia humana totalmente alienada.

Los logros del progreso desafían tanto la denuncia como la justificación ideológica; ante su tribunal, la 'falsa conciencia' de su racionalidad se convierte en la verdadera conciencia. Esta absorción de la ideología por la realidad no significa, sin embargo, el 'fin de la ideología'. Por el contrario, la cultura industrial avanzada es, en un sentido específico, más ideológica que su predecesora, en tanto que la ideología se encuentra hoy en el propio proceso de producción. Bajo una forma provocativa, esta proposición revela los aspectos políticos de la racionalidad tecnológica predominante. El aparato productivo, y los bienes y servicios que produce, 'venden' o imponen el sistema social como un todo. ${ }^{19}$

19 Marcuse, 1969, op.cit., p. 33 
Pero aunque la ideología en el sentido de falsa conciencia total parece dejar sin resquicios de libertad a la humanidad, en cuyo caso El hombre unidimensional sería sólo un discurso pesimista que cierra todas las posibles salidas de la alienación, pensamos que sí mantiene la dialéctica presentada. La salida en esta obra, como lo había sido en Eros y civilización, es el arte. «Como la tecnología, el arte crea otro universo de pensamiento y práctica contra y dentro del existente. Pero en contraste con el universo técnico, el universo artístico es un universo de ilusión, apariencia, Schein. Sin embargo, esta apariencia es semejanza de una realidad que existe como amenaza y promesa de la establecida». ${ }^{20}$ La ideología en tanto ilusión, en tanto posibilidad, en tanto señalamiento de alternativas a la alienación se muestra en el arte vinculado intrínsecamente a la técnica. «Y, en la medida en que los valores estéticos son los valores no agresivos por excelencia, el arte como tecnología y técnica implicaría la aparición de una racionalidad nueva en la construcción de una sociedad libre, es decir, la aparición de modos y de fines nuevos en el propio progreso técnico». ${ }^{21}$

También en otros textos posteriores a El hombre unidimensional retoma la noción de ideología en su carácter dialéctico, en su posición utópica, como posibilidad de una revolución.

Y como la represión se extiende y aplasta a toda la población sometida, la tarea intelectual, la tarea de discusión y de educación, la tarea de desgarrar no sólo el velo tecnológico sino también los demás velos tras los cuales operan la dominación y la represión, todos estos factores 'ideológicos' se transforman en verdaderos factores materiales de una transformación radical. ${ }^{22}$

\section{Algunas RePercusiones EN LA TeORÍA POLÍticA ACTUAL}

Terry Eagleton describe el concepto de ideología desde la perspectiva de Marcuse como una «parodia», como «un sistema 'totalitario' que ha gestionado y desvirtuado todo conflicto social». ${ }^{23}$ Pensamos que aun con la única referencia de El hombre unidimensional, alcanza para considerar a la ideología de modo complejo y a esta definición de Eagleton como parcial y simplificada.

La complejidad del concepto es recuperada por Kellner, para quien la «crítica de la ideología» en Marcuse se identifica con el concepto mismo de «teoría crítica». Señala también que hay cierta ambigüedad en el uso que hace del término «ideología» en El hombre unidimensional porque lo usa en lo que

20 Ibid. p. 253

21 Marcuse, Herbert. La sociedad opresora. Caracas, Tiempo Nuevo, 1970. p. 189

22 Marcuse, Herbert. La sociedad industrial y el marxismo. Buenos Aires, Quintaria, 1969 b, p.50

23 Eagleton, Terry. (1997) Ideología. Una introducción. Barcelona, Paidós, 2005. p. 170 
él llama el sentido clásico marxista, como mistificación y legitimación de la realidad social para perpetuar la dominación de clase, como por ejemplo la ideología del positivismo. Otro sentido es el que señala la absorción de la ideología en la realidad, describiendo a la ciencia y la tecnología como ideológicas, es decir que la ideología estaría contenida también en el proceso de producción y consumo ${ }^{24}$. Sugerimos que Kellner no repara en que esta interpretación de la ideología no es ambigua sino dialéctica y que ya se encuentra en el propio Marx, tal como hemos señalado. Además Kellner considera que la noción de ideología se perfecciona en textos posteriores a El hombre unidimensional, como «Industrialización y capitalismo en Max Weber». Aunque esta sentencia no puede considerarse errónea, apostamos a que la noción de ideología que hemos presentado ya estaba de algún modo instalada en su artículo de 1941: «Algunas implicaciones sociales de la tecnología moderna». ${ }^{25}$ La ideología es de carácter dialéctico y se inscribe en la sociedad industrial avanzada en el sistema de producción científico-tecnológico.

En este punto se hace imprescindible introducir a Jürgen Habermas en su texto de 1968 inspirado en y dedicado a Marcuse: Ciencia y técnica como ideología. Para Habermas, en su interpretación y recuperación del pensamiento crítico de Marcuse, la ideología es inescindible de la ciencia y la tecnología. Para explicar esto comienza citando a Weber, para quien la «racionalización» depende del progreso de la ciencia y la técnica en las instituciones. Pero, afirma Habermas,

Marcuse está convencido de que en lo que Max Weber llamaba 'racionalización', no se implanta la 'racionalidad' en tanto que tal, sino que en nombre de la racionalidad lo que se impone es una determinada forma de oculto dominio político. Como la racionalidad de este tipo sólo se refiere a la correcta elección entre estrategias, a la adecuada utilización de tecnologías y a la pertinente instauración de sistemas (en situaciones dadas para fines dados), lo que en realidad hace es sustraer la trama social global de intereses en la que se eligen estrategias, se utilizan tecnologías y se instauran sistemas a una reflexión y reconstrucción racionales. Aparte de eso, esa racionalidad sólo se refiere a las situaciones de empleo posible de la técnica y exige por ello un tipo de acción que implica dominio, ya sea sobre la naturaleza o sobre la sociedad. La acción racional con respecto a fines es, por su estructura misma, ejercicio de controles. ${ }^{26}$

24 Cfr. Kellner, Douglas. Herbert Marcuse and the Crisis of Marxism. California, University of California Press, 1984. p. 255

25 Cfr. Marcuse, Herbert. (2001) Guerra, Tecnología y Fascismo. Textos inéditos. Medellín, Universidad de Antioquía.

26 Habermas, Jürgen. (1968) Ciencia y técnica como «ideología», Madrid, Tecnos, 1984. p. 55 
Para Habermas esta idea de Marcuse de que la racionalidad de la ciencia se ha formado históricamente se encuentra en la línea de pensamiento inaugurada por Husserl y Heidegger. «Pero sólo Marcuse convierte el contenido político de la razón técnica en punto de partida analítico para una teoría de la sociedad del capitalismo tardío $\gg{ }^{27}$. Habermas sintetiza la idea de Marcuse de una ciencia y una técnica nuevas, cualitativamente diferentes. Diferentes en su proyecto, en su método y fundamentalmente en su relación con la naturaleza. Sin embargo, duda de esta idea porque las realizaciones de la técnica, que considera son un proyecto humano y no de una época determinada, son irrenunciables. ${ }^{28}$

Por otra parte, Habermas pondera como importante la crítica de Marcuse a Weber, con relación a la necesidad de historizar el concepto de racionalización teniendo en cuenta la crítica de Marx a la ideología del capitalismo liberal. Esto porque, aun cuando se haya producido una transformación del capitalismo en monopólico, la crítica a la economía política sigue siendo imprescindible para su comprensión. En el nuevo contexto social, el progreso económico depende del progreso científico-técnico. La tesis de la tecnocracia ha

...podido penetrar como ideología de fondo en la conciencia de la masa despolitizada de la población y desarrollar su fuerza legitimatoria. El rendimiento peculiar de esta ideología consiste en que disocia la autocomprensión de la sociedad del sistema de referencia de la acción comunicativa y de los conceptos de la interacción simbólicamente mediada y los sustituye por un modelo científico. ${ }^{29}$

Este cambio en la sociedad capitalista, advierte Habermas, modifica el contenido y la forma de la ideología. Pues ahora la primera fuerza productiva, el progreso científico técnico sometido a control, se convierte él mismo en fundamento de la legitimación. Esta nueva forma de legitimación ha perdido, sin embargo, la vieja forma de la ideología.

La conciencia tecnocrática es, por una parte, menos ideológica que todas las ideologías precedentes; pues no tiene el poder opaco de una ofuscación que sólo aparenta, sin llevarla a efecto, una satisfacción de intereses. Pero por otra parte, la ideología de fondo, más bien vidriosa, dominante hoy, que convierte en fetiche a la ciencia, es más irresistible que las ideologías de viejo cuño, ya que con la eliminación de las cuestiones prácticas no solamente justifica el interés parcial de dominio de una determinada clase y reprime la necesidad parcial de

27 Ibid. p. 59

28 Ibid.p. 63

29 Ibid. pp. 88-89 
emancipación por parte de otra clase, sino que afecta al interés emancipatorio como tal de la especie. ${ }^{30}$

La racionalidad tecnológica protagoniza la ideología, cuestionando el concepto de racionalización. Para Habermas, la crítica que realizan Adorno y Horkheimer a la Ilustración se ve llevada a su extremo por Marcuse al colocar a la ciencia y a la técnica en el lugar de la ideología.

En el capitalismo tardío se ha producido una cientifización de la técnica, lo cual significa un sistema único de ciencia y técnica intrínsecamente vinculado al capital y al Estado. En este sistema, el progreso científico-tecnológico se ha convertido en una fuente independiente de plusvalía. La ideología que subyace a la lógica tecnocrática de esta etapa del capitalismo promueve la despolitización de la población. Hasta aquí Marcuse. Pero Habermas toma su tesis y la interpreta desde el proyecto de su teoría de la acción comunicativa. La ideología analizada en este contexto «disocia la autocomprensión de la sociedad del sistema de referencia de la acción comunicativa y de los conceptos de la interacción simbólica mediada y los sustituye por un modelo científico», ${ }^{31}$ es decir que la ideología que promueve la tecnocracia permite un modelo político de resolución de tareas técnicas que se desentiende de las problemáticas prácticas. La ideología consiste en el ocultamiento de la diferencia entre los problemas técnicos y los prácticos, convirtiendo a la ciencia en un fetiche, que por lo mismo es legitimadora del sistema dominante.

Nos interesa mostrar aquí sólo el nexo entre Habermas y la teoría de la ideología de Marcuse en tanto aporte a la discusión epistemológica. Este nexo entre los autores y entre la ideología y la ciencia es señalado por J. Shapiro, ${ }^{32}, \mathrm{~J}$. Larraín ${ }^{33}$ y A. Cortina. ${ }^{34}$ Desde el punto de vista de Shapiro, también para Habermas la racionalidad tecnológica es la ideología legitimadora de la sociedad y considera que la teoría de Marcuse ha sido el punto de partida fundamental que le ha permitido a Habermas desarrollar su propia teoría.

Larraín, en cambio, destaca la crítica de Habermas a Marcuse, según la cual la crítica de la ideología del segundo, en tanto racionalidad tecnológica, es muy pesimista y conlleva una aporía. Lo sin salida se pone de manifiesto en la imposibilidad de modificar el curso actual de la ciencia y la tecnología y la falta de un sujeto de la revolución. Para Larraín la crítica a la ideología

30 Ibíd.pp. 96-97

31 Ibid. p. 89

32 Shapiro, Jeremy. «La dialéctica de la teoría y la práctica en la era de la racionalidad tecnológica: Herbert Marcuse y Jürgen Habermas». En: OLLMAN, Bertell y otros. Marx, Reich y Marcuse. Buenos Aires, Paidós, 1974.

33 Larraín, Jorge. (1979) El concepto de ideología. Vol. 3. Santiago, LOM ediciones, 2009.

34 Cortina, Adela. (1985) Crítica y utopía: La Escuela de Francfort. Madrid, Cincel, 1992. 
de la Escuela de Frankfurt en general es equivocada y fatalista. Creemos que esta interpretación se debe a una lectura lineal de la teoría crítica, que deja de lado sus elementos utópicos y emancipatorios.

Cortina, por su parte, destaca el hecho de que Marcuse lleva a su extremo la crítica a la racionalidad instrumental de la Escuela al postular que «la ciencia y la técnica realizan la función de ideología en el capitalismo tardío». ${ }^{35}$ Este diagnóstico es compartido por Habermas, aunque las soluciones difieran porque «Marcuse propone la creación de un nuevo tipo de ciencia y técnica, no dominador, sino liberador de la naturaleza; Habermas, por el contrario, está convencido de que el interés por dominar es compañero inseparable de la ciencia y de la técnica». ${ }^{36}$ Pero ambos coinciden, en la línea de Husserl, en que el interés por la dominación se encuentra inscrito en el desarrollo tecnológico de la racionalidad instrumental, enmascarado en la presunta neutralidad valorativa de la ciencia.

Los tres intérpretes coinciden en que la solución de Habermas al problema de la ciencia y la técnica como ideología supera a la lectura marcuseana. No es nuestro objeto evaluar aquí dicha afirmación pero sí nos interesa poner de relieve que la teoría de Marcuse es el fundamento de la teoría de Habermas en este respecto, lo que permite decir que el problema de la racionalidad tecnológica constituye un elemento central de la teoría crítica, no sólo en Marcuse sino también como nexo o bisagra con la denominada segunda Escuela de Frankfurt.

Queremos destacar sin embargo la insistencia de Marcuse en la necesidad de historizar, de introducir dialécticamente la historia en los conceptos que determinan el desarrollo de la racionalidad occidental. Esto permite desnaturalizar lo dado y reivindicar las posibilidades no represivas de la ciencia y la técnica en el siglo XXI. Al mismo tiempo permite pensar la teoría marxista de modo no ortodoxo, es decir, considerando que los cambios históricos producidos en el capitalismo, por un lado no la invalidan, pero por otro lado tampoco la fijan. La teoría marxista puede ser reinterpretada, resignificada, destacando algunas de sus tesis a la luz de una comprensión situada, históricamente determinada.

Lo antedicho permite todavía seguir pensando en uno de los puntos que ha generado mayor conflicto por parte de los críticos de Marcuse, incluyendo al propio Habermas: el hecho de que la ciencia y la técnica contengan en sí mismas el interés de la dominación. O quizá, y con esto sigue la discusión abierta, este hecho haya sido históricamente determinado en Occidente:

Pero si la razón técnica se revela como razón política, ocurre únicamente porque desde el comienzo era esta razón técnica y esta razón política: determinada y

35 Ibid. p. 99

36 Ibid. p. 100 
limitada por el preciso interés del dominio. En cuanto razón política, la razón técnica es histórica. Si la separación de los medios de producción es una necesidad técnica, no lo es la servidumbre organizada a través de la misma. ${ }^{37}$

Con todo, pensar en conjunto a la ideología y a la ciencia, conlleva la doble ventaja de, por un lado, vincular a la ciencia con la política, interés central de nuestro estudio, y por otro lado, mantener abierta la discusión, también desde la epistemología, de la fructífera categoría de ideología para la crítica social. Este encuentro permite mostrar además la necesidad del trabajo conjunto del pensamiento, de modo no reduccionista ni fragmentario, para la comprensión crítica de la totalidad social.

Natalia Fischetti es Doctora en Filosofía por la Universidad Nacional de Córdoba.

\section{Linea de investigación}

Epistemología crítica en el marco de una beca posdoctoral del Consejo Nacional de Investigaciones Científicas y Técnicas (CONICET, Argentina).

\section{Publicaciones recientes}

Fischetti, Natalia. «La filosofía en tensión. Marcuse contra Wittgenstein». En: Dossier Paralaje, Revista electrónica de filosofía. Vol. 3, pp. 6-19, Valparaíso. Chile, 2009. ISSN 0718-6770

Fischetti, Natalia. "La dialéctica entre los instintos y la razón en el pensamiento de Herbert Marcuse. Eros, Tánatos y la ciencia». En: Cuadernos del Sur-Filosofía. (UNS) ISSN 1668-7434 (en prensa)

Dirección electrónica: nfischetti@mendoza-conicet.gob.ar

37 Marcuse, 1970, op.cit. p. 35 